\title{
Strategies for Teaching Professional Ethics to IT Engineering Degree Students and Evaluating the Result
}

\author{
Rafael Miñano · Ángel Uruburu • Ana Moreno-Romero \\ Diego Pérez-López
}

\begin{abstract}
This paper presents an experience in developing professional ethics by an approach that integrates knowledge, teaching methodologies and assessment coherently. It has been implemented for students in both the Software Engineering and Computer Engineering degree programs of the Technical University of Madrid, in which professional ethics is studied as a part of a required course. Our contribution of this paper is a model for formative assessment that clarifies the learning goals, enhances the results, simplifies the scoring and can be replicated in other contexts. A quasi-experimental study that involves many of the students of the required course has been developed. To test the effectiveness of the teaching process, the analysis of ethical dilemmas and the use of deontological codes have been integrated, and a scoring rubric has been designed. Currently, this model is also being used to develop skills related to social responsibility and sustainability for undergraduate and postgraduate students of diverse academic context.
\end{abstract}

Keywords Engineering education - Engineering ethics - Formative assessment . Professional codes of ethics 


\section{Introduction}

The special issue of Science and Engineering Ethics on "Perspectives on Teaching Social Responsibility to Students in Science and Engineering" presented some indication that the overall impact of the external demands for teaching social responsibility and professional ethics has been limited and that there is no evidence that the method by which universities are preparing engineering students in these topics is adequate or sufficient. The existing accreditation and external evaluation mechanisms do not ensure that the curricula establish appropriate teaching goals for professional ethics and social responsibility (Zandvoort et al. 2013). There are various reasons that these topics assume a marginal role in the engineering curriculum. Some are related to the contextual, ill-structured, complex or interdisciplinary character of the ethical and social problems. However, some authors highlight the challenge of assessment (Finelli et al. 2012; Goldin et al. 2015). The courses that include significant attention to ethics are often treated as "soft courses," with fewer exams and assignments than other courses. This practice sends a message that ethical issues are not important (Colby and Sullivan 2008; Fabregat 2013).

This paper presents an experience of endeavoring to influence these situations and contribute to changing the "marginal role" of professional ethics and social responsibility in our context of teaching engineering. This attempt was undertaken in a required course for freshmen of both the Software Engineering and Computer Engineering degree programs of the Technical University of Madrid (hereafter termed UPM). This course concentrates on the legal issues that are related to Information Technologies, although some topics concerning sustainability, social responsibility and professional ethics have been included. Accepting the time constraints, we have designed a comprehensive strategy that integrates the acquisition of significant knowledge and skills by engineering students and the development of appropriate active learning methodologies and formative assessment.

Our work has several specific objectives. The first is to design a model of assessment that is aligned with both the instructional activities and the learning outcomes. This model should simplify the process of introducing professional ethics competences to current engineering teaching and be applicable in diverse contexts: small and large groups, standard courses and project based courses, and different topics (ethical, social or environmental issues). The second objective is to assess the effectiveness of our teaching strategies by grading the level of improvement in the ethical skills that our students achieve in the course. The final objective is to study the effects of some methodological factors, such as the use of professional codes of conduct or the practice effects of the dilemmas that are analyzed in the tests.

This paper is structured as follows: in "Knowledge, Methodologies and Evaluation of the Teaching of Engineering Ethics" section, the literature about teaching engineering ethics is reviewed, focusing on essential knowledge and skills, learning methodologies and assessment methods that have been proved to be most effective. "Context of the Experience" section explains the context of the teaching 
and evaluation experience. "Methodology" section describes the methodology that was used to design our model for assessment and to conduct the study for testing the effectiveness of the teaching process. The quantitative results are presented and discussed in "Results and Discussion" section. Finally, conclusions drawn from the experience are summarized and some avenues of further research are outlined.

\section{Knowledge, Methodologies and Evaluation of the Teaching of Engineering Ethics}

Universities acquire legitimacy in society by producing professionals who have an extensive knowledge of their subject and are willing to be guided in practice by the values and goals that give meaning to their profession. Therefore, teaching ethics at a university must emphasize professional ethics (Cortina 2007). In this sense, Rudnicka et al. (2013) quote Gilligan's words to state that moral development in the college years must center, therefore, on a shift from ideology to moral and ethical responsibility. In the case of engineering studies, students must be prepared and empowered to use technology responsibly. It is the responsibility of universities to make our future engineers ethically aware and competent (Rathje et al. 2008).

With the aim of educating responsible engineers, it can be said that the ethics component is inherently linked to other knowledge areas, such as social responsibility, sustainability, business ethics, technology assessment and, of course, engineering ethics.

In regard to an individualistic approach, we can summarize the main knowledge required in workplace ethics or micro-ethics as the deontological and ethical principles (Davis 2006; Sleurs 2008), the professional codes of ethics (BesterfieldSacre et al. 2000; Colby and Sullivan 2008; Herkert 1999), and an understanding of the risks, impacts and ethical issues that are related to engineering solutions (Brey 2012; ENAEE 2015; Rudnicka et al. 2013; Wright 2011). However, paying attention to both the meso and macro level, topics like corporate social responsibility, science technology and society, social justice, equity, human rights, public goods, empowerment of people or environmental sustainability, are included (Bucciarelli 2008; Conlon 2008, 2010; Didier and Derouet 2013; Herkert 2001; Mitchell and Baillie 1998; Ozaktas 2013; Rathje et al. 2008; Yau et al. 2013; Zandvoort 2008; Zandvoort et al. 2013).

As to the essential skills, there is consensus on the relevance of ethical sensitivity, ethical judgment and reasoning, making informed ethical choices, applying professional knowledge according to deontological and ethical principles, holistic perspective, and communication and dialogic skills (Besterfield-Sacre et al. 2000; Davis 2006; ENAEE 2015; Rudnicka et al. 2013; Shuman et al. 2004, 2005). Intuitionism introduces personal constraints (emotions, motivations and experience) and social constraints (anchors, representations and pressures) as essential factors in the decision-making process. Some authors consider that the assumption that ethical decision-making is exclusively rational is unlikely to be sufficient to prepare individuals to make ethical decisions in conditions of equivocality and uncertainty. They suggest that emotional regulation and self-reflection are also important skills 
to be trained (Haidt 2001; Salvador and Folger 2009; Sonenshein 2007; Thiel et al. 2012).

In regard to the most efficient teaching methodologies to develop ethical skills, there is a general agreement in the literature on the convenience of using active learning practices. To be more effective, these practices should be linked to appropriate theoretical and empirical inputs, and the educational goals should be explicit (Bowden and Smythe 2008; Colby and Sullivan 2008; Davis 2006; Rathje et al. 2008; Segalas 2009; Segalas et al. 2010; Zandvoort 2008; Zandvoort et al. 2013).

Within these methodologies, one specific teaching tool is highlighted. It is the use of cases that are framed as moral dilemmas. When working with cases, the professors must select problematic situations that are as emotionally engaging as possible, and ask the student to discuss and reflect on the values that the case involves. The case can be real or hypothetical, but always must be open and challenging (Colby and Sullivan 2008; Han and Jeong 2014; Liebert 2013; Ozaktas 2013). Thiel et al. (2013) studied the influence of emotional case content in casebased ethical training and found that cases with emotional content stimulates their retention and facilitates the transfer of ethical decision-making principles.

The benefits of this methodology are diverse. The discussion of ethical dilemmas familiarizes the person with the most significant ethical questions, both social and professional (Lozano et al. 2006). Working with cases is a useful method to understand moral theory, the application of different ethical perspectives or the introduction of professional deontological codes in order to analyze, and create a solution to, an ethical dilemma (Colby and Sullivan 2008; Mumford et al. 2008; Rathje et al. 2008; Yau et al. 2013). Dealing with cases involves reasoning and judgment, but also is very useful to develop other important skills. The communication and dialogic skills can be enhanced by taking advantage of the group's interactions and dialogic methodology (Bowden and Smythe 2008; Lozano et al. 2006; Rudnicka et al. 2013). The strategy-based learning that Mumford et al. (2008) propose uses the analysis of cases to develop emotional and self-reflection skills, and other useful strategies for ethical decision making: recognizing complexity, anticipating the consequences of actions on others, seeking outside help or considering different perspectives.

The assessment of ethical development is a challenge for teachers and researchers (Finelli et al. 2012; Goldin et al. 2015; Sonenshein 2007). In view of the academic context, various authors (Colby and Sullivan 2008; de la Herrán Gascón 2014; Rudnicka et al. 2013; Shuman et al. 2005) suggest that students should be assessed on their knowledge and skills in solving ethical dilemmas in engineering contexts, but not on values, beliefs, character or actual behavior. Moreover, there is widespread recognition that the educational goals related to professional ethics cannot be achieved completely during the undergraduate years. Thus, it must be assumed that only a "relative improvement" (for instance, in ethical awareness, sensitivity or judgment) can be achieved by training students in specific strategies. However, this does not ensure that the students will then act ethically (Bowden and Smythe 2008; Colby and Sullivan 2008; Davis 2006). 
Nevertheless, Finelli et al. (2012) present some valid instruments for assessing both positive and negative ethical behavior. There are different kinds of instruments to assess ethical competences, such as those that assess a student's general level of moral development, reasoning or judgment (Kohlberg 1981, 1984; Rest and Narvaez 1998; Comunian 2002) or those that survey moral values as reviewed by Rudnicka (2004). Other tools concentrate on assessing the ethical decision making process, such as the one that was validated by Mumford et al. (2006), More recently, Keefer et al. (2014) designed a formative tool, the Decision Procedure Checklist with a Scoring Guide, which emphasizes the alignment of learning outcomes, instructional activities and assessment. Goldin et al. (2015) have evaluated the validity and reliability of a new assessment instrument that stresses the acquisition of moral problem-solving methods to identify, analyze and resolve dilemmas that arise when there are conflicting ethical, social or technical values $\mathrm{c}$.

The most widely used tool to measure moral development is the Rest's Defining Issues Test (DIT). It is based on Kohlberg's comprehensive theory of moral development. It proposes four sequential steps for making ethical decisions. They are: (1) the identification of ethical dilemmas (recognizing), (2) ethical evaluation (judgment), (3) deciding whether to act ethically or unethically (moral intention) and (4) performing the ethical action (behavior) (Rest 1979, 1986). However, none of the dilemmas used in the current version of DIT (DIT-2) are related to engineering ethics (Rest and Narvaez 1998). An adaptation in the field of engineering is the Engineering and Science Issues Test, designed by Borenstein et al. (2010). An important limitation of these tests is that they focus mainly on moral reasoning and judgment and neither on other important skills for ethical decision making nor on broader aspects of professional engineering ethics.

The Pittsburgh-Mines Engineering Ethics Assessment Rubric (PMEAR Rubric) is an appropriate tool for assessing students' abilities to resolve complex, openended ethical dilemmas of professional engineering practice. Beyond the reasoning skills, it provides measures of some other useful abilities for ethical decision making. This scoring rubric was developed by a team of researchers in engineering, philosophy and bioethics from the University of Pittsburgh and the Colorado School of Mines. Research has supported its validity as a measure of ethical reasoning for engineering dilemmas. It has five components: (1) recognition of dilemma, (2) information, (3) analysis, (4) perspective and (5) resolution. Its scores range from 1 to 5 (Shuman et al. 2004).

The experience that is presented in this paper has integrated the main topics that were reviewed previously in our context of the IT Engineering Degrees of the UPM. As can be seen in the following sections, we have included-in the syllabus of a required course - knowledge related to professional ethics from both a micro and a macro ethics approaches. Our students have developed some skills for ethical decision-making by the analysis of cases framed as ethical dilemmas. As we have time constraints for these topics and because of the introductory level of our teaching context, we have concentrated on reasoning skills and the use of deontological codes as an appropriate option (Sonenshein 2007). The students' progress has been assessed by following a model that synthesizes some of the above 
proposals, with a simplified schema Identify-Analyze-Decide. It has been scored by using a rubric that has been adapted from the PMEAR Rubric.

\section{Context of the Experience}

The Spanish universities are integrated into the European Higher Education Area (hereafter termed EHEA). Consequently, they have included in every Bachelor's and Master's degree program the Dublin Descriptors that the European Ministers of Education have adopted. Some of its learning outcomes are relevant to education for professional ethics (EHEA 2005). In addition, each Spanish university determines a set of generic competences that must be developed in every degree program. Some universities have defined competences that are directly or indirectly related to professional ethics or social responsibility, such as "responsible and ethical

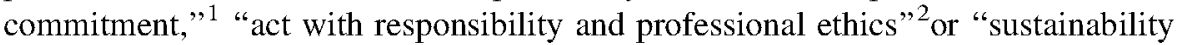
and social commitment." 3 The UPM has included as a generic competence "respect for the environment" in all of its degree programs.

In relation to specific degrees, the Spanish Council of Universities makes recommendations about the competences that students should acquire during their studies for each official degree. For example, the recommendations for the degrees that are related to IT Engineering include such competences as "the capacity to understand and apply the ethical responsibility, legislation and professional deontology of computing engineering" and the "ability to analyze and assess the social and environmental impact of technical solutions" (BOE 2009). Some universities and colleges incorporate these recommendations differently in specific compulsory or elective subjects, including modules in technical courses or, in a transversal way, in the Final Year Project. Globally, the effective integration of these competences into the programs is a challenge. They still play a "marginal role" in the curriculum.

The programs of both the Software Engineering and the Computer Engineering degrees of the UPM, that provided the experience that is described in this paper, include the aforementioned recommendations. The design of these eight-semester degree programs that were developed in 2009 according to the EHEA is based largely on the Curriculum Guidelines of the Association for Computing Machinery (ACM). The ACM encourages the inclusion of ethical and social issues at the core of the curriculum. It makes very specific proposals concerning required and optional modules, and the introduction of determined topics in other technical courses (ACM 2013; Tucker 1991).

Following ACM's recommendations, "Social, Legal, Ethical and Professional Issues" is a required subject ( 6 ECTS $)^{4}$ in the first year of both the Software Engineering and the Computer Engineering degree programs of the UPM. During

\footnotetext{
${ }^{1}$ Universidad de Valladolid: www.uva.es.

${ }^{2}$ Universidad de Extremadura: www.unex.es.

3 Universitat Politècnica de Catalunya: www.upc.edu.

${ }^{4}$ European Credit Transfer System, that represents 25-30 h of student's work.
} 
the course, the students must develop the generic competences "respect for the environment" and "critical thinking", which are compulsory in UPM, and those that are recommended by the Spanish Council of Universities for IT engineering degree programs (BOE 2009). Among the course's learning outcomes are "make professional decisions adjusted to deontological codes" and "have the ability to gather and interpret relevant data to inform judgments that include reflection on relevant social, legal and ethical issues."

The course syllabus includes different topics that are related to the professional performance of IT engineering and its relationship to society. These are the legal issues, such as intellectual property and data protection, that form the core of the subject. Since 2009, ethical and social issues feature more prominently in the content of the course and, represented in 2013-2014 the equivalent of 1 ECTS and $25 \%$ of the final grade. The students become familiar with engineering professional values, professional codes of ethics, the social and environmental global impact of IT, the digital divide and the basic principles of Corporate Social Responsibility. In that way, individualistic, organizational and global approaches have been integrated. Some relevant constraints are the limited number of lessons that are devoted to engineering ethics and the professors' lack of expertise in teaching those "non technical subjects". It must be said that the UPM has no specific department for social or humanities subjects.

Throughout the course, active learning methodologies are used to foster student participation. These include frequent debates in the classroom, case discussions, dilemmas, monographs, expert lectures or visits to UPM research centers, such as the Digital Accessible Home or the CITSEM (Software Technology Center and Multimedia Systems for Sustainability), where their work has a significant social impact.

The programs of both the Software Engineering and the Computer Engineering degree of the UPM were updated in 2014-2015 and include, as a new generic competence, "social and environmental responsibility," instead of the former "respect for the environment." It has been defined as the "knowledge, skills and attitudes needed to integrate into the profession, the social, environmental and ethical issues that affect IT engineering in a responsible and balanced way" and it is intended to provide a thoughtful approach to the ethical and social aspects of IT engineering (Minano and Fernández Aller 2015). The development of the competence has been assigned to two compulsory courses of 3 ECTS, "Ethical and Social Issues" in the 2nd semester and "Legal and Professional Issues" in the 5 th semester. The "social and environmental responsibility" is also included among the competences that must be assessed in the Final Year Project (FYP).

\section{Methodology}

Our overall goal is to provide effective means for students to acquire skills related to engineering ethics and social responsibility and to find an appropriate model for evaluation. In the first stage, we designed a model for assessment that is applicable in different contexts, aligned to, and consistent with the learning outcomes above 
mentioned. Then, based upon this model, a scoring rubric has been designed and refined. This is explained in detail in "Design of the Model and the Scoring Rubric" section.

For the second stage, in order to evaluate the teaching's effectiveness of the model, we have chosen a quasi-experimental pretest-posttest design. This design was considered the most appropriate one for our context, means and goals, focused on the teaching and learning activity. It includes activities and data collection that have been repeated in two consecutive semesters as explained in "QuasiExperimental Design" Sect.

\section{Design of the Model and the Scoring Rubric}

We have made an effort to synthesize the key dimensions for an assessment model that is aligned with our learning outcomes and simple, clear and applicable in different academic contexts. As our students are freshmen, we have considered an introductory level and have focused on reasoning skills and the use of deontological codes as an appropriate option (Sonenshein 2007). Moreover, it is consistent with two of our course's learning outcomes: "make professional decisions adjusted to deontological codes" and "have the ability to gather and interpret relevant data to inform judgments that include reflection on relevant social, legal and ethical issues."

We have defined three basic sequential components and a transversal fourth component. For the basic components, our main references have been the PMEAR Rubric (Shuman et al. 2004), the Rest's four steps for making ethical decisions (Rest 1986), the ABET's criteria (Besterfield-Sacre et al. 2000), the strategy-based learning proposed by Mumford et al. (2008) and the stages of the ETICA approach (Brey 2012; Stahl 2011).

- Identification: identify and describe the issues and ethical dilemmas that arise in the situation. This is very similar to the "recognition of dilemma" attribute of the PMEAR Rubric, but goes beyond the specific dilemma by recognizing other issues that are related to the situation. It is similar to the first step of both the Rest's proposal and the ETICA approach.

- Analysis: integrates the evaluation stages of Rest's proposals, ABET's criteria and the ETICA approach. This summarizes the attributes "information," "analysis" and "perspective" of the PMEAR Rubric. Depending on the context, the indicators that are best adapted to the characteristics of the activity proposed should be defined. In our study, we added some of the strategies that were proposed by Mumford et al. (2008). These included considering all stakeholders, different points of view, the consequences (risks and benefits) of different perspectives and stakeholders and the appropriate use of ethical principles.

- Decision: this is very similar to the "resolution" attribute of the PMEAR Rubric. It can be considered to be equivalent to the third stage of Rest's proposals, ABET's criteria and the ETICA approach. However, the proposed solution must be feasible and consistent with professional ethical principles and/or current regulations,./ Also, it should consider some references from diverse ethical 
perspectives, such as the utilitarian (assessing consequences) or the contractual ("win-win" proposals).

The last component is:

- Knowledge of professional codes of ethics. This transversal dimension considers the selection of the articles that are related to the situation studied, a correct explanation of this relation and a proper the use of the most relevant articles for the analysis and decision making. It is based upon the ABET's criteria (Besterfield-Sacre et al. 2000; Herkert 1999), the proposal of Colby and Sullivan (2008) and the rubric that is applied to assess the Contemporary Ethical Issues Focus of the University of Hawai'i Manoa (UH Manoa 2008).

Using these four components, we have defined a scoring rubric that is adapted to our teaching context in which the students' progress is assessed by the analysis of ethical dilemmas (Minano and Fernández Aller 2015). The rubric's scores range from 1 to 4 to be coherent with the scoring that is used in our university in measuring the attainment of competences. Our criteria are as follows:

(1) Identification: At the lowest level, respondents do not identify any problem or dilemma that arises in the situation. Alternatively, if they do, they do it incorrectly. At the highest level, they clearly identify the key problems and dilemmas, describe them properly and mention values and ethical principles that are in conflict.

(2) Analysis: The base level is used for instances where there is no analysis or where the analysis is oversimplified (only one point of view is provided and without arguments). The ideal case provides a deep and reasoned analysis. It considers all of the stakeholders, different points of view, the consequences (risks and benefits) for different perspectives and stakeholders and an appropriate use of ethical principles.

(3) Decision: The lowest level is for students who provide no solution at all, propose a solution that is contrary to the most elementary ethical principles, or make a decision without any justification. In the best case, the solution is consistent with the highest ethical principles, is well justified in comparison to other alternatives. Also, its consequences or potential risks have been considered and it is oriented to achieving a "win-win" situation.

(4) Use of Professional Codes of Ethics: The first level makes no reference to any code of ethics or any reference is incorrect. Ideally, applicable sections of the professional codes are correctly cited and their meaning and/or implications in forming a judgment and/or making a decision are explained.

During this first stage, the rubric was refined. After the initial test in the first semester, a sample was revised by two members of the research team, scores were compared and some confusing details were changed. The main improvements were intended to simplify the evaluation criteria (selecting the key aspects to assess in 
each dimension), to adapt them to the most frequent student responses (observed in the sample) and to facilitate discrimination between levels.

Finally, we must say that, when evaluating with this rubric, the emphasis should not be on the final solution, but on the reasoning process, the understanding of multiple factors to consider and the arguments of both the analysis and the decisionmaking (Colby and Sullivan 2008; Goldin et al. 2015).

\section{Quasi-Experimental Design}

We used the rubric with the students of the "Social, Legal, Ethical and Professional Issues" course during the 2013-2014 academic year. In the first semester (Computer Engineering Degree), 80 of the 135 students agreed to take part in the study. In the second semester (Software Engineering Degree), 110 students of the 164 students participated in the study. In each semester, the lessons were received in three different groups, although the instructor for the topics related to professional ethics and social issues was the same for each group. Most of our student's age was between 18 and 20 years (it is a first year course) and less than $10 \%$ of the participants were females. Therefore, we have not analyzed age or gender as factors.

On the first day of the course and following a general presentation, the students were asked to participate in the study as part of an educational innovation project to improve their competences in social and environmental responsibility. The students were told that participation was voluntary and would not influence their marks in the course. Although the training activities were integrated in the course and the study's final test was part of one of the course's three exams, the analysis that we conducted for our study was separate from the scoring of the exam. The participants provided their informed consent on that first day, when they agreed to take the initial test.

In both semesters, the following methodology was used:

I. An initial test (PRE-Test). On the first day of the course, the statement of a professional ethical dilemma related to computer engineering was given to the students and they were asked to:

- Identify the ethical issues that appear in the situation that is described and the dilemma that the professional faces.

- Analyze the situation taking into account all important aspects needed to make a decision.

- Propose and justify the decision that the practitioner should make.

I. Competence development. This has been integrated into the regular activities of the course in the following manner:

- Exposition and discussion of the principles and issues of professional ethics in the field of engineering $(4 \mathrm{~h})$. We also presented two codes of ethics that are related to computer engineering (ACM; IEEE). The same teacher taught every group in both semesters. 
- Working in small groups to discuss different ethical dilemmas that are related to computer engineering using ethical $\operatorname{codes}^{5}(2 \mathrm{~h})$. There was further discussion with the large group and input from the teacher.

- Individual homework about other professional ethical dilemma. This work was evaluated using the rubric criteria that were explained previously. These criteria were accessible for the students in the statement of the homework as we wanted the rubric to be a guide for the students. Well in advance of the final test, a solution which included comments was given by the teacher and some of the students' essays that were considered most relevant were published.

- The students were encouraged to use the professional codes of ethics when analyzing dilemmas, both in working groups and in individual homework (see the statement of activities in the "Appendix").

III. A final test (POST-Test). As a part of one of the course exams, a professional ethical dilemma was proposed. The statement was the same as that in the initial test (see I). In this case, the students were permitted to consult the codes of ethics of the ACM and IEEE, but were not required to.

Within this general framework, there were specific differences between the two semesters.

In the first semester, the same dilemma was proposed for both the initial and the final tests. However, in order to study the influence of the dilemmas on the results and a possible "practice effect", we worked with two different dilemmas in the second semester. In the PRE test, both cases were randomly assigned. In the POST test, the same cases were randomly assigned in such a way that the four possible combinations had the same number of students.

Another significant difference in the second semester was the statement of activities that were undertaken during the course for development of competences. What the students had to do was stated more explicitly, especially with regard to analysis, decision-making and how to use the professional codes of ethics (see "Appendix"). However, the statement of both the PRE and the POST tests remained the same in both semesters (see I).

The variables defined are shown in Table 1. For both the initial and the final Tests, we have defined three variables for each basic attribute of the rubric: Identify, Analyze and Decide. The variable Sum adds the scoring of the former variables. To quantify the differences between the POST and the PRE variables, we defined the correspondent variables IMPROVEMENT. To obtain more detailed information, we also defined a variable no. of IMPROVEMENTS, this counts the number of the three basic attributes that have increased in level.

In addition, we defined two variables to score the use of codes of conduct according to the 4th attribute of the rubric. The variable CODE ranged 1 to 4 , according the 4th

\footnotetext{
5 The proposed dilemmas have been taken from (Johnson 2009), http://www.onlineethics.org/Resources/ Cases.aspx and some proper dilemmas adapted from current issues, such as the case of the whistle-blower Edward Snowden and the spying network.
} 
Table 1 Variables (ranks) that are defined in the quasi-experimental design in both semesters

\begin{tabular}{|c|c|c|c|}
\hline & PRE test & POST test & Difference POST - PRE \\
\hline $\begin{array}{l}\text { Scoring the } 3 \text { basic } \\
\text { attributes }\end{array}$ & $\begin{array}{l}\text { Identify-PRE } \\
(1-4) \\
\text { Analyze-PRE } \\
\quad(1-4) \\
\text { Decide-PRE } \\
(1-4)\end{array}$ & $\begin{array}{l}\text { Identify-POST } \\
(1-4) \\
\text { Analyze-POST } \\
\quad(1-4) \\
\text { Decide-POST } \\
(1-4)\end{array}$ & $\begin{array}{l}\text { Identify-IMPROVEMENT }(-3,3) \\
\text { Analyze-IMPROVEMENT }(-3,3) \\
\text { Decide-IMPROVEMENT }(-3,3)\end{array}$ \\
\hline $\begin{array}{l}\text { Global scoring the basic } \\
\text { attributes }\end{array}$ & $\begin{array}{l}\text { Sum-PRE } \\
(3-12)\end{array}$ & $\begin{array}{l}\text { Sum-POST } \\
\quad(3-12)\end{array}$ & $\begin{array}{l}\text { Sum-IMPROVEMENT }(-9,9) \\
\text { No. of IMPROVEMENTS }(0-3)\end{array}$ \\
\hline Using the codes of ethics & & $\begin{array}{l}\text { CODE }(1-4) \\
\text { CODE-01 }(0-1)\end{array}$ & \\
\hline $\begin{array}{l}\text { Influence of the dilemma } \\
\text { used }\end{array}$ & $\begin{array}{l}\text { CASE-PRE } \\
\text { (A-B) }\end{array}$ & $\begin{array}{l}\text { CASE-POST } \\
\text { (A-B) }\end{array}$ & $\begin{array}{l}\text { CASE-INTERACTION (AA-AB- } \\
\text { BA-BB) }\end{array}$ \\
\hline
\end{tabular}

component of the rubric. The variable CODE-01 takes a value of 0 for a poor use of the codes (no use or inadequate or too simple use of codes, values 1 and 2 in the rubric), and it takes a value of 1 for a good use of the codes (citing applicable sections of the professional codes and explaining their meaning and/or implications in forming judgments and/or making decisions, values 3 and 4 in the rubric).

Finally, the variables CASE-PRE, CASE-POST and CASE-INTERACTION, are defined to assist the study of the influence of the dilemmas that were proposed in the test.

\section{Results and Discussion}

The study's most relevant quantitative results in both semesters and their discussion are presented in the following paragraphs.

\section{Effectiveness of the Teaching: Results}

Some descriptive data of the scores for the three attributes that are defined in the rubric appear in Tables 2 and 3.

Figure 1 compares the PRE-Test and POST-Test results, and shows a statistically significant increase for each dimension in both semesters. The differences between components in the same test are not statistically significant.

Figure 2 presents the results for the relative frequencies that will permit a more thorough analysis of the students' progress in each component.

To have a global view of the students' progress, see Fig. 3 for the data concerning the variable SUM, which adds the scores of the three dimensions. It is remarkable that the upper quartile of the variable SUM in the PRE test is less than, or equal to, the lower quartile of the variable SUM in the POST test.

A One-Way ANOVA analysis has been made to compare the results for the variable SUM in the PRE test to those in the POST test. For this variable, the 
Table 2 Descriptive data for the three basic components in the first semester $(N=80)$

\begin{tabular}{|c|c|c|c|c|c|c|c|c|c|c|}
\hline \multirow[t]{2}{*}{ Attribute } & \multirow[t]{2}{*}{ Rank } & \multicolumn{3}{|l|}{ PRE test } & \multicolumn{3}{|c|}{ POST test } & \multicolumn{3}{|c|}{ IMPROVEMENT } \\
\hline & & Median & Mean & SD & Median & Mean & SD & Median & Mean & SD \\
\hline Identify & $1-4$ & 2 & 1.94 & 0.66 & 3 & 2.77 & 0.63 & 1 & 0.94 & 0.75 \\
\hline Analyze & $1-4$ & 2 & 1.95 & 0.84 & 3 & 2.75 & 0.80 & 1 & 0.78 & 1.05 \\
\hline Decide & $1-4$ & 2 & 2.2 & 0.72 & 3 & 2.84 & 0.70 & 1 & 0.64 & 0.88 \\
\hline Sum & $3-12$ & 6 & 6.09 & 1.63 & 8 & 8.34 & 1.54 & 2 & 2.25 & 1.82 \\
\hline
\end{tabular}

Table 3 Descriptive data for the three basic components in the second semester $(\mathrm{N}=110)$

\begin{tabular}{|c|c|c|c|c|c|c|c|c|c|c|}
\hline \multirow[t]{2}{*}{ Attribute } & \multirow[t]{2}{*}{ Rank } & \multicolumn{3}{|l|}{ PRE test } & \multicolumn{3}{|c|}{ POST test } & \multicolumn{3}{|c|}{ IMPROVEMENT } \\
\hline & & Median & Mean & SD & Median & Mean & $\mathrm{SD}$ & Median & Mean & $\mathrm{SD}$ \\
\hline Identify & $1-4$ & 2 & 1.9 & 0.51 & 3 & 2.71 & 0.79 & 1 & 0.81 & 0.88 \\
\hline Analyze & $1-4$ & 2 & 2.03 & 0.78 & 2 & 2.52 & 0.80 & 0 & 0.49 & 0.89 \\
\hline Decide & $1-4$ & 2 & 2.22 & 0.67 & 3 & 2.90 & 0.70 & 1 & 0.67 & 0.85 \\
\hline Sum & $3-12$ & 6 & 6.15 & 1.48 & 8 & 8.13 & 1.80 & 2 & 1.97 & 1.79 \\
\hline
\end{tabular}

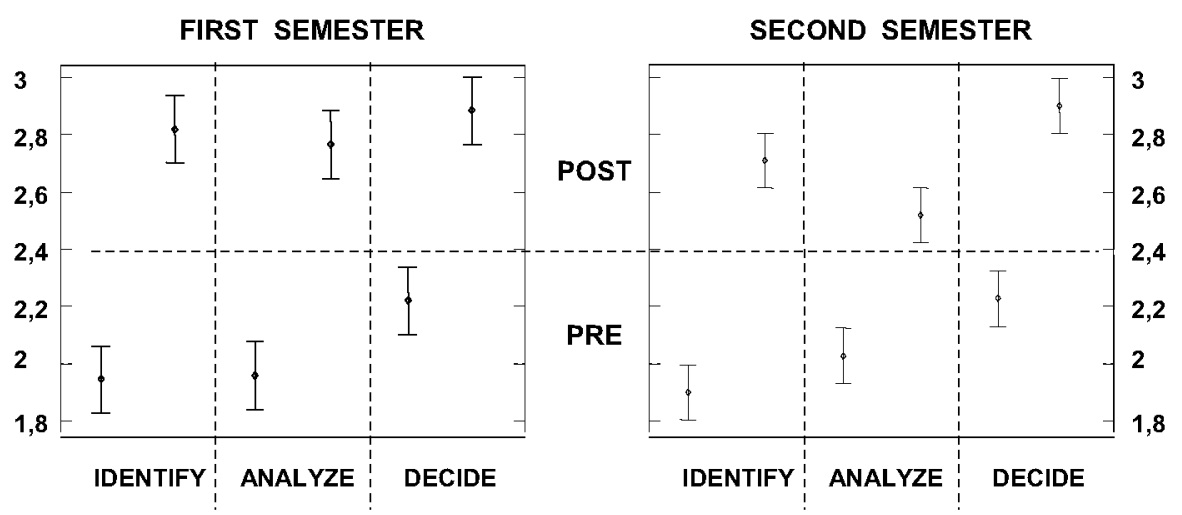

Fig. 1 Comparison of the PRE and POST test means by a $95 \%$ LSD Interval for each component and both semesters

normality and homoscedasticity of the residuals have been checked and the diagnosis of the model was found to be correct. There is a statistically significant difference between the means of the variable SUM from the PRE-Test and those of the POST-Test at the $95 \%$ confidence level (Table 4).

To study the statistical significance of the improvements, Table 5 provides the results of the hypothesis test for the variable SUM-IMPROVEMENT, which rejects the null hypothesis that the mean equals 1 versus the alternative hypothesis that the mean is greater than 1 . 
Relative Frequencies. First semester

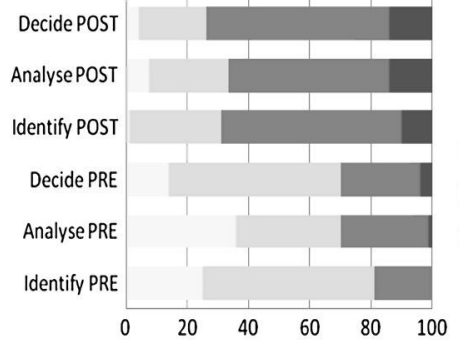

Relative Frequencies. Second semester

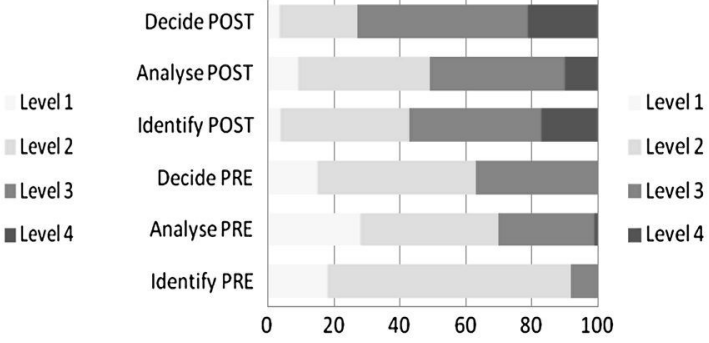

Fig. 2 Percentage of students for each level (1-4), in every dimension in PRE and POST-Test
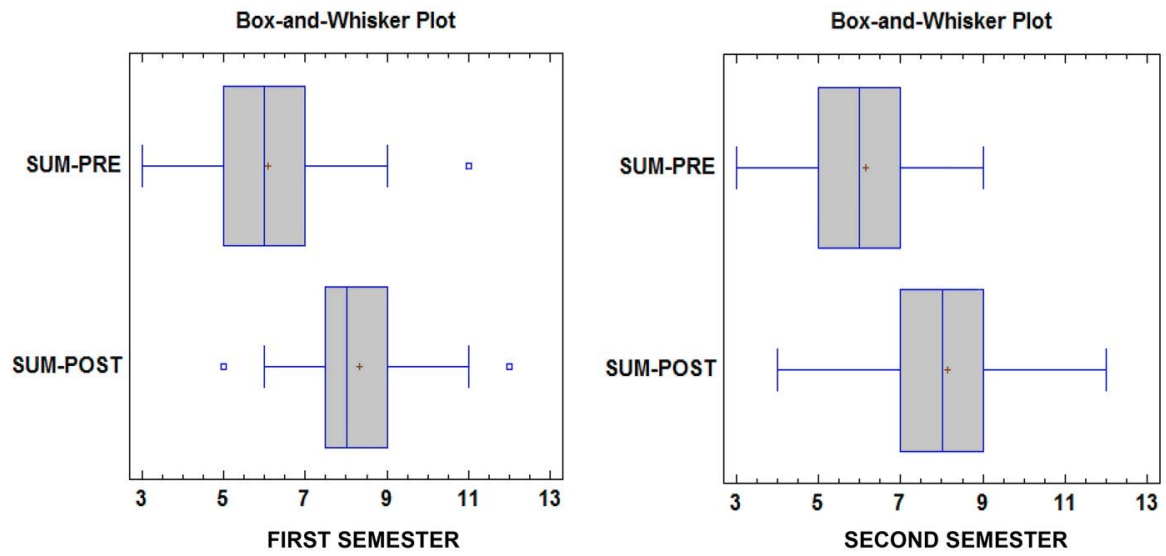

Fig. 3 Box-and-Whisker Plot for the variable SUM, comparing its performance in the PRE and POST tests in both semesters

Table 4 ANOVA table for SUM by PRE-POST in both semesters

\begin{tabular}{|c|c|c|c|c|c|c|c|c|c|c|}
\hline \multirow[t]{2}{*}{ Source } & \multicolumn{5}{|c|}{ First semester } & \multicolumn{5}{|c|}{ Second semester } \\
\hline & $\begin{array}{l}\text { Sum of } \\
\text { Squares }\end{array}$ & $D f$ & $\begin{array}{l}\text { Mean } \\
\text { square }\end{array}$ & F-ratio & $p$ value & $\begin{array}{l}\text { Sum of } \\
\text { squares }\end{array}$ & $D f$ & $\begin{array}{l}\text { Mean } \\
\text { square }\end{array}$ & F-ratio & $p$ value \\
\hline $\begin{array}{r}\text { Between } \\
\text { groups }\end{array}$ & 202.5 & 1 & 202.5 & 80.33 & 0.0000 & 214.041 & 1 & 214.041 & 78.74 & 0.0000 \\
\hline $\begin{array}{l}\text { Within } \\
\text { groups }\end{array}$ & 398.275 & 158 & 2.52073 & & & 592.591 & 218 & 2.71831 & & \\
\hline $\begin{array}{l}\text { Total } \\
\text { (Corr.) }\end{array}$ & 600.775 & 159 & & & & 806.632 & 219 & & & \\
\hline
\end{tabular}

A different approach is used to analyze the frequencies of the variable no. of IMPROVEMENTS. The number of attributes in which a student has improved his level is counted gathering the data from the two semesters. 
Table 5 Hypothesis tests ( $t$ test) for SUM-IMPROVEMENT

\begin{tabular}{|c|c|c|c|c|c|c|}
\hline & $\mathrm{N}$ & Mean & $\mathrm{SD}$ & $\begin{array}{l}\text { Computed } \mathrm{t} \\
\text { statistic }\end{array}$ & $p$ value & Conclusion \\
\hline First semester & 80 & 2.25 & 1.82459 & 6.1276 & $1.21363 \mathrm{E}-7$ & \multirow{2}{*}{$\begin{array}{l}\text { Reject the null hypothesis } \\
\text { for alpha }=0.05\end{array}$} \\
\hline Second semester & 110 & 1.97273 & 1.79428 & 5.68588 & $1.50989 \mathrm{E}-7$ & \\
\hline
\end{tabular}

Null hypothesis: mean $=1.0$, Alternative: greater than

Table 6 Absolute and relative frequencies of the no. of the IMPROVEMENTS variable for the combined semesters

\begin{tabular}{llllll}
\hline No. of IMPROVEMENTS & $\mathrm{N}$ & 0 & 1 & 2 & 3 \\
\hline Absolute frequency & 190 & 17 & 57 & 69 & 47 \\
Relative frequency $(\%)$ & 100 & 8.94 & 30 & 36.32 & 24.74 \\
\hline
\end{tabular}

\section{Effectiveness of the Teaching: Discussion}

In the second stage of our study, we attempted to assess the effectiveness of our teaching strategies by grading the level of improvement in the ethical skills that our students had achieved in the course. From the results shown in "Effectiveness of the Teaching: Results" section, we confirmed our students' progress, as we have found statistically significant differences between the results of the initial and the final tests (Table 4; Fig. 3).

In quantifying these improvements, we considered our four-level scoring rubric. Overall, by integrating the results of the three basic components studied, the average increase is about two levels (bringing together the data of both semesters, the average increase of the variable SUM is 2.08). In addition, there is evidence of progress of at least one level in at least one attribute (Table 5). The data presented in Table 6, confirms the global progress, as it shows that more than $90 \%$ of the students have improved in some items and nearly $25 \%$ have improved in all attributes.

If we focus on the progress in each attribute of the competence, the data show statistically significant differences in all attributes between the results of the initial and final tests (Fig. 1). The best level is reached in the decision component and the greatest improvement was in the identification of ethical issues. We do not find these results to be surprising, as the work developed in the classroom affects the knowledge of the diverse ethical problems that arise in the field of engineering far more than the others components. Therefore, it is reasonable that the greatest change occurred in the dimension that is most directly influenced by that knowledge.

The dimension of analysis received the lowest level. We believe that this is due to its complexity and dependence on other generic skills, such as critical thinking and holistic vision. These results are consistent with the explanations that were given by Rudnicka et al. (2013) as a result of their research, which states that the recognition of an ethical dilemma is typically taught only in engineering ethics 
courses, whereas the analysis is a function that students learn to use throughout the curricula. We observed during the course's activities that students found difficulties to reflect, to analyze and, to consider different points of view. They prioritized to provide a solution to professors more than to explain the reasoning aspects of the particular case?

The progress in each attribute has been also quantified. Although the average improvement is somewhat less than one (Tables 2,3), the medians vary from 2 to 3 in most cases. That is, more than $50 \%$ of the students had a level that was greater than, or equal to, 3 for every attribute in the final test. The data in Fig. 2 also confirm the effectiveness of our methodology, as the percentage of students at the minimum level (1) has been reduced significantly in all dimensions and the number of students who have achieved the highest level (4) is significantly higher.

\section{Knowledge of Professional Codes: Results}

Another goal of this study was to assess the influence of the knowledge and the use of professional codes of ethics in the development of abilities for engineering ethics. Our hypothesis was that an appropriate use of these codes is directly related to an improvement in the different dimensions defined to assess those skills.

We present the data from the second semester because, as we explained previously, we made some relevant changes in the semester that concern the use of the professional codes of ethics for both analysis and decision-making (see "Appendix"). Table 7 presents the descriptive data of the variable CODE related to the use of codes of conduct. It was explained in "Quasi-Experimental Design" section.

The discrete character of the variable CODE and the sample size don't permit us to give valid results concerning a statistically significant correlation or dependence of the variables that are related to the basic attributes. So, we present only descriptive data. Figure 4 shows the average values for the improvements in each attribute for the different values of the variable CODE.

It must be mentioned that, in the final test, students were able to use the codes that they considered to be appropriate. There was no explicit reference to them in the statement, because we were interested in determining how students use them on their own initiative. The results show that there were students who made no explicit reference to the codes (e.g., level 1), but provided an acceptable analysis and

Table 7 Frequency tabulation for the variable CODE in the second semester

\begin{tabular}{lll}
\hline CODE & & \\
\hline Values & Frequency & Relative frequency (\%) \\
\hline 1 & 19 & 17.27 \\
2 & 30 & 27.27 \\
3 & 46 & 41.82 \\
4 & 15 & 13.64 \\
& $\mathrm{~N}=110$ & 100 \\
\hline
\end{tabular}


Fig. 4 Means of the improvement of each attribute for the different levels of the variable CODE. Data from the second semester $(\mathrm{N}=110)$
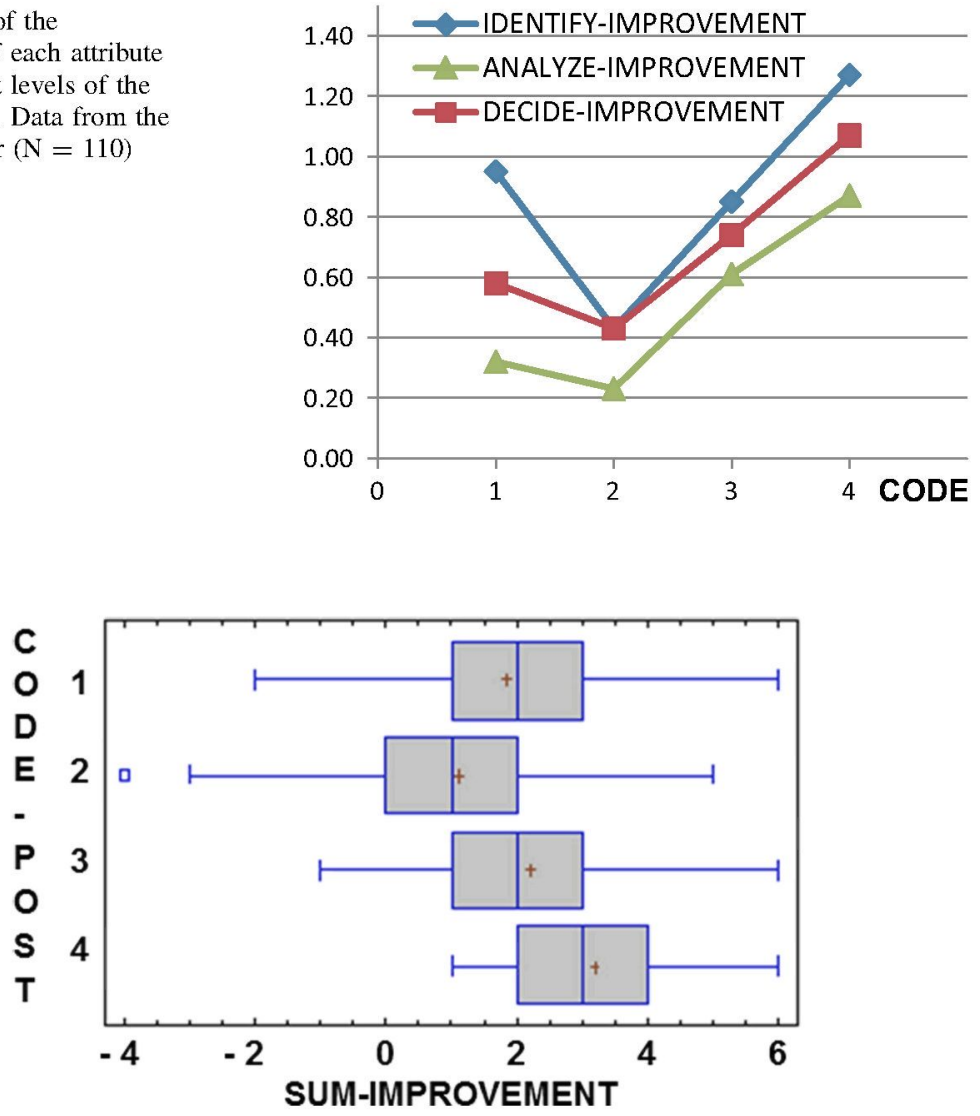

Fig. 5 Box-and-Whisker Plot of variable SUM-IMPROVEMENT for the different levels of the variable CODE. Data from the second semester $(\mathrm{N}=110)$

argument for the decision. Apart from that, a direct relation between the values 2-34 of the variable CODE and the means of the attributes improvements can be seen: the greater the level of the variable CODE, the greater are the improvement in all attributes.

When comparing the variable CODE to the variable SUM-IMPROVEMENT, the same direct relationship can be seen. Figure 5 presents the Box-and-Whisker Plot for the variable SUM-LMPROVEMENT for each value of the variable CODE (1-4). The plot shows that students with a level 4 in variable CODE make better progress and the variable SUM-IMPROVEMENT have the lowest variability.

Some statistically significant results can be obtained by using the variable CODE-01, as the sample size allows comparisons by using a hypothesis test. Table 8 shows the results of comparing the averages improvement in the variables of the students with a poor use of the codes and those with a good use of the ethical codes. There are statistically significant differences $(\alpha=0.05)$ in every case, except for the variable Identify-IMPROVEMENT $(p=0.06)$. 
Table $8 t$ test for comparison of means, $\mathrm{H}_{0}: \mu_{0}=\mu_{1}, \mathrm{H}_{1}: \mu_{0} \neq \mu_{1}$, for each component improvement

\begin{tabular}{|c|c|c|c|c|c|c|c|c|c|}
\hline \multirow[t]{2}{*}{ CODE-01 } & \multirow[t]{2}{*}{$\mathrm{N}$} & \multicolumn{2}{|c|}{$\begin{array}{l}\text { Identify } \\
\text { IMPROVEMENT }\end{array}$} & \multicolumn{2}{|c|}{$\begin{array}{l}\text { Analyze } \\
\text { IMPROVEMENT }\end{array}$} & \multicolumn{2}{|c|}{$\begin{array}{l}\text { Decide } \\
\text { IMPROVEMENT }\end{array}$} & \multicolumn{2}{|c|}{$\begin{array}{l}\text { Sum } \\
\text { IMPROVEMENT }\end{array}$} \\
\hline & & Mean & $\begin{array}{l}t \text { test } \\
p \text { value }\end{array}$ & Mean & $\begin{array}{l}t \text { test } \\
p \text { value }\end{array}$ & Mean & $\begin{array}{l}t \text { test } \\
p \text { value }\end{array}$ & Mean & $\begin{array}{l}t \text { test } \\
p \text { value }\end{array}$ \\
\hline 0-Poor use & 49 & 0.63 & 0.0600 & 0.27 & 0.0159 & 0.49 & 0.0418 & 1.39 & 0.0019 \\
\hline 1-Good use & 61 & 0.95 & & 0.67 & & 0.82 & & 2.44 & \\
\hline
\end{tabular}

\section{Knowledge of Professional Codes: Discussion}

The data presented above support the hypothesis that the use of professional deontological codes is a powerful method to teach professional ethics at an introductory level. From the descriptive analysis, the expected direct relationship between the quality of the use of the codes and the improvement in every basic component has been observed: the higher the score for the use of the codes, the higher is the average level in the improvement of identifying, analyzing and making decisions.

When we classified the students into two groups, the ones with a poor use of the codes and those with a good use, the data showed some statistically significant differences between them when their means for each basic attribute and their improvements are compared. We can infer from these results that a good use of ethical codes mainly facilitates better analysis and decision-making.

\section{Influence of the Dilemma Selected: Results}

In the second semester, we used two different dilemmas in both the initial and the final test for studying a possible "practice effect". In the PRE test, the dilemmas were randomly assigned. In the POST test, the same cases were randomly assigned in such a way that the four possible combinations had the same number of students. The variables CASE-PRE and CASE-POST assume a value of A or B, depending on the case assigned to the student in the PRE-Test and POST-Test respectively. ${ }^{6}$

First, we compared the means of all variables for each case, A or B, by a $t$ test with a null hypothesis of $\mu_{\mathrm{A}}=\mu_{\mathrm{B}}$ and the alternative $\mu_{\mathrm{A}} \neq \mu_{\mathrm{B}}$. Table 9 presents the results of the initial test. There are statistically significant differences in the variables Analyze, Decide and Sum, with the best results obtained by the students who worked with dilemma A. In the final test, the students with the case B obtained higher values on average. However, the differences in this case were not statistically significant (see Table 10).

We also conducted tests of independence with the CASE-INTERACTION variable, which represents the possible combinations of dilemmas in the PRE and POST tests. Table 11 shows that the hypothesis of independence was rejected for all attributes.

\footnotetext{
${ }^{6} \mathrm{~A}$ : The same case than was adapted in the first semester from the "Software Design Testing" case (http://www.onlineethics.org/cms/7883.aspx. Accessed 31 July 2015).

B: Prepared from a real case about the design of a network of pollution control in a Spanish city (Minano and Fernández Aller 2015).
} 
Table 9 PRE test: $t$ test for comparison of means, $H_{0}: \mu_{A}=\mu_{B}, H_{1}: \mu_{A} \neq \mu_{B}$, for every variable

\begin{tabular}{|c|c|c|c|c|c|c|c|c|c|}
\hline \multirow[t]{2}{*}{ CASE-PRE } & \multirow[t]{2}{*}{$\mathrm{N}$} & \multicolumn{2}{|c|}{ Identify PRE } & \multicolumn{2}{|c|}{ Analyze PRE } & \multicolumn{2}{|c|}{ Decide PRE } & \multicolumn{2}{|c|}{ Sum PRE } \\
\hline & & Mean & $\begin{array}{l}t \text { test } \\
p \text { value }\end{array}$ & Mean & $\begin{array}{l}t \text { test } \\
p \text { value }\end{array}$ & Mean & $\begin{array}{l}t \text { test } \\
p \text { value }\end{array}$ & Mean & $\begin{array}{l}t \text { test } \\
p \text { value }\end{array}$ \\
\hline A & 59 & 1.92 & 0.7355 & 2.17 & 0.0400 & 2.46 & 0.0001 & 6.54 & 0.0028 \\
\hline B & 51 & 1.88 & & 1.86 & & 1.96 & & 5.70 & \\
\hline
\end{tabular}

Table 10 POST test: $t$ test for comparison of means, $\mathrm{H}_{0}: \mu_{\mathrm{A}}=\mu_{\mathrm{B}}, \mathrm{H}_{1}: \mu_{\mathrm{A}} \neq \mu_{\mathrm{B}}$, for every variable

\begin{tabular}{|c|c|c|c|c|c|c|c|c|c|}
\hline \multirow[t]{2}{*}{ CASE-POST } & \multirow[t]{2}{*}{$\mathrm{N}$} & \multicolumn{2}{|c|}{ Identify POST } & \multicolumn{2}{|c|}{ Analyze POST } & \multicolumn{2}{|c|}{ Decide POST } & \multicolumn{2}{|c|}{ Sum POST } \\
\hline & & Mean & $\begin{array}{l}t \text { test } \\
p \text { value }\end{array}$ & Mean & $\begin{array}{l}t \text { test } \\
p \text { value }\end{array}$ & Mean & $\begin{array}{l}t \text { test } \\
p \text { value }\end{array}$ & Mean & $\begin{array}{l}t \text { test } \\
p \text { value }\end{array}$ \\
\hline A & 53 & 2.72 & 0.92 & 2.47 & 0.5584 & 2.75 & 0.0546 & 7.94 & 0.3031 \\
\hline B & 57 & 2.70 & & 2.56 & & 3.03 & & 8.30 & \\
\hline
\end{tabular}

Table 11 Test of independence for the possible combinations of dilemmas in the PRE and POST tests and the results for the basic attributes $\left(\mathrm{N}_{\mathrm{AA}}=27, \mathrm{~N}_{\mathrm{AB}}=32, \mathrm{~N}_{\mathrm{BA}}=26, \mathrm{~N}_{\mathrm{BB}}=25\right)$

\begin{tabular}{lccc}
\hline Tests of independence $\mathrm{X}^{2}$ for CASE-INTERACTION (AA, BB, AB and BA) & \\
\hline Variable & Statistic & Df & $p$ value \\
\hline IDENTIFY-POST & 5.314 & 9 & 0.8062 \\
ANALYSE-POST & 5.659 & 9 & 0.7735 \\
DECIDE-POST & 10.590 & 9 & 0.3049
\end{tabular}

The sample sizes are not exactly alike because that there were students who did the initial test, but did not the final test

\section{Influence of the Dilemma Used: Discussion}

When attempting to determine if the dilemmas used in the test influence the results, no evidence was found of dependence between the interactions between the dilemmas analyzed in the PRE and the POST test and the various basic dimensions studied. The students who conducted both tests of the same dilemma had no significant advantage over students who worked on different dilemmas (Table 11).

We found some significant differences due to the dilemma in the initial test. However, in the final test, the differences were not statistically significant and, surprisingly, they were in the opposite direction. The significant differences in the PRE test may be due to the moral level of intensity, which was slightly higher in case B, the worst performing case. Both cases have a moral of medium-low intensity. They are very similar in four of the characteristics that were determined by Jones (1991). Case B is somewhat more complex in two characteristics, social consensus and proximity. 
These results lead us to state that the ethical training that was provided during the course tends to balance the differences that appeared in the initial tests. Again, our interpretation is consistent with one of the results of the research of Rudnicka et al. (2013), who point out that knowing engineering ethics is critical for situations involving lower moral intensity decisions.

\section{Conclusions and Further Research}

In this paper, we have presented our experience in developing professional competences in ethics in freshman IT engineering degree students. We have a comprehensive strategy that includes knowledge, skills, teaching methodologies and formative assessment. Our main contribution is a model of assessment that focuses on three basic dimensions of ethical competences: identification of the problems (ethical sensitivity), analysis and reflection on them (ethical reasoning) and decision (ethical decision-making). We have added a fourth dimension that is related to the knowledge and adequate use of deontological codes. This model is consistent with the main learning outcomes of professional ethics, at an introductory level, and reinforces its achievement Also, it has been helpful to teachers in evaluating students' performance and it can be used in diverse academic contexts.

In the first stage of our study, we designed a rubric that has proven to be effective in assessing the progress of our students' abilities related to professional ethics. In the second stage, we have used this assessment tool to measure that progress by means of a quasi-experimental design of pre- and post-tests, with a large sample of our students in two semesters of the 2013-2014 academic year. We have confirmed the students' progress, as we have found statistically significant differences between the results of the initial test and the final test. Most of the students have improved by at least one level (according to our scoring rubric) in one or more of the three basic dimensions and $25 \%$ of them have improved in all of them. The most significant improvement occurred in the attribute of identifying ethical problems, which is more directly related to the training in engineering ethics. The least improvement occurred in analysis, which is the most complex dimension and one that requires working with diverse strategies and skills. As was expected, knowledge of codes of ethics is directly related to the improvement in all dimensions. In addition, we have observed that the teaching and the learning activities help to reduce the differences that were identified in the initial test in relation to the dilemma studied.

At present, we are working to improve and to adapt this model to other contexts where skills that are related to social responsibility and sustainability must be developed. Our current research is aimed at introducing this model for the assessment of the Final Year Project of several degree and master's degree programs at the UPM. The report of these projects includes a mandatory chapter with reflections on aspects of social responsibility, environmental sustainability and professional ethics related to that work. We evaluate how the students identify the potential social and environmental impacts; how they analyze and value, and, finally, how they integrate all of this in an engineering solution. In addition, some compulsory subjects concerning engineering projects have 
incorporated this model during the course of the 2014-2015 academic year. As this work is not at the introductory level, the challenge is to find the appropriate methodologies with which to give effective strategies to students to develop projects in ethically and socially responsible ways.

Acknowledgments This research was conducted within the National Program of Projects Fundamental Research under the Sixth National Program for Scientific Research, Development and Technological Innovation (Reference No. EDU2012-31080). It was funded by the Ministry of Science and Innovation of Spain. We thank also the Educational Innovations Projects of the UPM. They had supported and funded since 2012 several experiences for developing competences of ethical, social and environmental responsibility for students of IT engineering degrees. In addition, the first author would like to acknowledge María Jesús Sánchez Naranjo for her comments on previous drafts of this paper.

\section{Appendix: Statement About the Work in Small Groups and Individual Homework}

In the second semester, we explained more explicitly what the students had to do, especially in their analysis (2) and decision-making (3).

First semester.

(2) Identify articles from professional ethical codes that may be appropriate for the assessment of the behavior of the practitioner in that case. Justify the selection, using, at least, the ACM Code.

(3) Propose the decision that a good practitioner should make and justify it.

Second semester.

(2) Analyze the situation taking into account every important aspect in making a decision.

To do this:

- Identify the different actors involved (personal or collective), how the situation affects them and how the possible solutions can affect them, ...

- Select articles of ethical codes that are related to the situation and state why. Also, identify values, ethical and deontological principles that can guide the decision.

- Analyze the situation from different viewpoints or perspectives.

(3) Propose the decision that a good practitioner should make and justify it.

To do this:

- Identify principles and ethical values and some articles from the ethical codes to support it.

- Assess the consequences and potential risks of it.

- Explain why it is preferable to other options. 


\section{References}

ACM-Association for Computing Machinery. (2013). Computer science curricula 2013. Curriculum guidelines for undergraduate degree programs in computer science. Retrieved from http://www. acm.org/education/CS2013-final-report.pdf. Accessed July 30, 2015.

ACM-Association for Computing Machinery. (2015). Code of ethics and professional conduct. Retrieved from http://www.acm.org/about/code-of-ethics. Accessed July 30, 2015.

Barnett, T. (2001). Dimensions of moral intensity and ethical decision making: An empirical study. Journal of Applied Social Psychology, 31(5), 1038-1057.

Besterfield-Sacre, M., Shuman, L. J., Wolfe, H., et al. (2000). Defining the outcomes: A framework for EC-2000. IEEE Transactions on Engineering Education, 43(2), 100-110.

BOE-Boletín Oficial del Estado. (2009). Recomendaciones para la propuesta por las universidades de memorias de solicitud de títulos oficiales en los ámbitos de la ingeniería informática, ingeniería técnica informática e ingeniería química. Secretaría General de Universidades. Acuerdo de 8 de junio de 2009. Retrieved from http://www.boe.es/diario_boe/txt.php?id=BOE-A-2009-12977. Accessed July 30, 2015.

Borenstein, J., Drake, M. J., Kirkman, R., \& Swann, J. L. (2010). The engineering and science issues test (ESIT): A discipline-specific approach to assessing moral judgment. Science and Engineering Ethics, $16(2), 387-407$.

Bowden, P., \& Smythe, V. (2008). Theories on teaching \& training in ethics. Electronic Journal of Business Ethics and Organization Studies, 13(2), 19-26.

Brey, P. A. (2012). Anticipating ethical issues in emerging IT. Ethics and Information Technology, 14(4), 305-317.

Bucciarelli, L. L. (2008). Ethics and engineering education. European Journal of Engineering Education, 33(2), 141-149.

Colby, A., \& Sullivan, W. M. (2008). Ethics teaching in undergraduate engineering education. Journal of Engineering Education, 97(3), 327-338.

Comunian, A. L. (2002). Structure of the Padua moral judgment scale: A study of young adults in seven countries. In 110th annual conference of the American Psychological Association, Chicago, IL.

Conlon, E. (2008). The new engineer: Between employability and social responsibility. European Journal of Engineering Education, 33(2), 151-159.

Conlon, E. (2010). Towards an integrated approach to engineering ethics. In Proceeding of the 3rd international symposium for engineering education.

Cortina, A. (2007). Ética de la razón cordial: educar en la ciudadanía en el siglo XXI. Oviedo: Ediciones Nobel.

Davis, M. (2006). Integrating ethics into technical courses: Micro-insertion. Science and Engineering Ethics, 12(4), 717-730.

de la Herrán Gascón, A. (2014). Enfoque radical e inclusivo de la formación. REICE: Revista Electrónica Iberoamericana sobre Calidad, Eficacia y Cambio en Educación, 12(2), 163-264.

Didier, C., \& Derouet, A. (2013). Social responsibility in French engineering education: A historical and sociological analysis. Science and Engineering Ethics, 19, 1577-1588.

EHEA-European Higher Education Area. (2005). The framework of qualifications for the European Higher Education Area. Retrieved from http://www.ehea.info/Uploads/Documents/QF-EHEAMay2005.pdf. Accessed July 30, 2015.

ENAEE-European Network for Accreditation of Engineering Education. (2015). EUR-ACE framework standards and guidelines. Retrieved from http://www.enaee.eu/eur-ace-system/eur-ace-frameworkstandards. Accessed July 30, 2015.

Fabregat, J. (2013). Explicit training in human values and social attitudes of future engineers in Spain. Science and Engineering Ethics, 19(4), 1551-1556.

Finelli, C. J., Holsapple, M. A., Ra, E., Bielby, R. M., Burt, B. A., Carpenter, D. D., et al. (2012). An assessment of engineering students' curricular and co-curricular experiences and their ethical development. Journal of Engineering Education, 101(3), 469-494.

Goldin, I. M., Pinkus, R. L., \& Ashley, K. (2015). Validity and reliability of an instrument for assessing case analyses in bioengineering ethics education. Science and Engineering Ethics, 21(3), 789-807.

Haidt, J. (2001). The emotional dog and its rational tail: A social intuitionist approach to moral judgment. Psychological Review, 108(4), 814-834. 
Han, H., \& Jeong, C. (2014). Improving epistemological beliefs and moral judgment through an STSbased science ethics education program. Science and Engineering Ethics, 20(1), 197-220.

Harris, C. E., Pritchard, M. S., \& Rabins, M. J. (2000). Engineering ethics: Concepts and cases (Vol. 2). Belmont, CA: Wadsworth.

Herkert, J. R. (1999). ABET's engineering criteria 2000 and engineering ethics: Where do we go from here. In Online proceeding of international conference on ethics in engineering and computer science (Vol. 2, pp. 1-24).

Herkert, J. R. (2001). Future directions in engineering ethics research: Microethics, macroethics and the role of professional societies. Science and Engineering Ethics, 7(3), 403-414.

IEEE-Institute of Electrical and Electronics Engineers. (2015). Code of ethics. Retrieved from http:// www.ieee.org/about/corporate/governance/p7-8.html. Accessed July 30, 2015.

Johnson, D. G. (2009). Computer ethics. New Jersey: Pearson Education.

Jones, T. M. (1991). Ethical decision making by individuals in organizations: An issue contingent model. Academy of Management Review, 16(2), 366-395.

Keefer, M. W., Wilson, S. E., Dankowicz, H., \& Loui, M. C. (2014). The importance of formative assessment in science and engineering ethics education: Some evidence and practical advice. Science and Engineering Ethics, 20(1), 249-260.

Kohlberg, L. (1981). The philosophy of moral development (Vol. 1). San Francisco: Harper \& Row.

Kohlberg, L. (1984). The psychology of moral development (Vol. 2). San Francisco: Harper \& Row.

Liebert, W. (2013). Preparing to understand and use science in the real world: Interdisciplinary study concentrations at the technical university of Darmstadt. Science Engineering Ethics, 19(4), 1533-1550.

Lozano, J. F., Palau, G., Gozálvez, V., \& Boni, A. (2006). The use of moral dilemmas for teaching agricultural engineers. Science and Engineering Ethics, 12(2), 327-334.

Minano, R., \& Fernández Aller, C. (2015). Guía para trabajar la competencia de responsabilidad social y ambiental. Retrieved from http://oa.upm.es/35542/. Accessed July 30, 2015.

Mitchell, C., \& Baillie, C. (1998). On values, role models, and the importance of being me. In Proceeding of the 1998 annual ASEE conference, June 28, 1998-July 1, 1998.

Mumford, M., Devenport, L., Brown, R., Antes, A., Hill, J., Connelly, S., et al. (2008). A sensemaking approach to ethics training for scientists: Preliminary evidence of training effectiveness. Ethics and Behavior, 18(4), 315-339.

Mumford, M. D., Devenport, L. D., Brown, R. P., Connelly, M. S., Murphy, S. T., Hill, J. H., et al. (2006). Validation of ethical decision-making measures: Evidence for a new set of measures. Ethics and Behavior, 16(4), 319-345.

Ozaktas, H. M. (2013). Teaching science, technology, and society to engineering students: A sixteen year journey. Science and Engineering Ethics, 19(4), 1439-1450.

Rathje, D., Spitzer, H., \& Zandvoort, H. (2008). How to prepare students for a responsible use of science and engineering. In Results from the workshop "teaching ethics and peace to science and engineering students". University of Hamburg, October 15-17, 2008.

Rest, J. R. (1979). Development in judging moral issues. Minneapolis, MN: Center for the Study of Ethical Development, University of Minnesota Press.

Rest, J. R. (1986). Moral development: Advances in research and theory. New York: Praeger Publishers.

Rest, J. R., \& Narvaez, D. (1998). Guide for DIT-2. Minneapolis, MN: Center for the Study of Ethical Development, University of Minnesota.

Rudnicka, E. (2004). A review of instruments for measuring moral reasoning/values. In 10th international conference on industry, engineering, and management systems (pp. 305-311).

Rudnicka, E. A., Besterfield-Sacre, M., \& Shuman, L. J. (2013). Development and evaluation of a model to assess engineering ethical reasoning and decision making. The International Joumal of Engineering Education, 29(4), 948-966.

Salvador, R., \& Folger, R. (2009). Business ethics and the brain. Business Ethics Quarterly, 19(1), 1-31.

Segalas, J. (2009). Engineering education for a sustainable future. Doctoral dissertation, PhD thesis, Universtat Politecnica de Catalunya, Barcelona.

Segalas, J., Ferrer-Balas, D., \& Mulder, K. F. (2010). What do engineering students learn in sustainability courses? The effect of the pedagogical approach. Journal of Cleaner Production, 18(3), 275-284.

Shuman, L. J., Besterfield-Sacre, M., \& McGourty, J. (2005). The ABET "professional skills" —Can they be taught? Can they be assessed? Journal of Engineering Education, 94(1), 41-55. 
Shuman, L. J., Sindelar, M. F., Besterfield-Sacre, M., Wolfe, H., Pinkus, R. L., Miller, R. L., et al. (2004). Can our students recognize and resolve ethical dilemmas? In CD Proceeding, 2004 American Society for Engineering Education conference.

Sleurs, W. (2008). Competences for ESD (education for sustainable development) teachers. A framework to integrate ESD in the curriculum of teacher training institutes. Comenius 2.1 project 118277-CP-12004-BE-Comenius-C2, 1.

Sonenshein, S. (2007). The role of construction, intuition, and justification in responding to ethical issues at work: The sensemaking-intuition model. The Academy of Management Review, 32(4), $1022-1040$

Stahl, B. C. (2011). IT for a better future: How to integrate ethics, politics and innovation. Journal of Information, Communication \& Ethics in Society, 9(3), 140-156.

Thiel, C. E., Bagdasarov, Z., Harkrider, L., Johnson, J. F., \& Mumford, M. D. (2012). Leader ethical decision-making in organizations: Strategies for sensemaking. Journal of Business Ethics, 107(1), $49-64$.

Thiel, C. E., Connelly, S., Harkrider, L., Devenport, L. D., Bagdasarov, Z., \& Johnson, J. F., et al. (2013). Case-based knowledge and ethics education: Improving learning and transfer through emotionally rich cases. Science and Engineering Ethics, 19(1), 265-286.

Tucker, A. B. (1991). Computing curricula 1991. Communications of the ACM, 34(6), 68-84.

UH Manoa-General Education. (2008). Contemporary ethical issues focus. Rubric for general education program assessment. Retrieved from http://manoa.hawaii.edu/assessment/resources/rubrics/ETH_ rubric_2008-04-04.doc. Accessed July 30, 2015.

UPM-Universidad Politécnica de Madrid-Innovación Educativa. (2015) Competencias genéricas. Recursos de apoyo al profesorado. http://innovacioneducativa.upm.es/competencias-genericas/ competencias. Accessed July 30, 2015.

Wright, D. (2011). A framework for the ethical impact assessment of information technology. Ethics and Information Technology, 13(3), 199-226.

Yau, J. J. C., Cheah, S.-M., \& Phua, S. T. (2013). Contextualize teaching of ethics in chemical engineering curriculum. In Proceeding of the 9th international CDIO conference.

Zandvoort, H. (2008). Preparing engineers for social responsibility. European Journal of Engineering Education, 33(2), 133-140.

Zandvoort, H., Børsen, T., Deneke, M., \& Bird, S. J. (2013). Editors' overview perspectives on teaching social responsibility to students in science and engineering. Science and Engineering Ethics, 19(4), $1413-1438$. 